\title{
Optimization of alkaline pretreatment and enzymatic hydrolysis for the extraction of xylooligosaccharide from rice husk
}

Nuntawat Khat-udomkiri ${ }^{1}$, Bhagavathi Sundaram Sivamaruthi ${ }^{1}$, Sasithorn Sirilun ${ }^{1}$, Narissara Lailerd ${ }^{1,2}$, Sartjin Peerajan ${ }^{3}$ and Chaiyavat Chaiyasut ${ }^{*}$

\begin{abstract}
Rice husk $(\mathrm{RH})$ is the major agricultural waste obtained during rice hulling process, which can be a sustainable source of xylooligosaccharide (XOS). The current study deals with the production of XOS from Thai rice husk using alkaline pretreatment and enzyme hydrolysis method. The response surface methodology consisted of central composite design and Box-Behnken design was employed to achieve the maximum response in alkaline pretreatment and XOS production, respectively. The optimum conditions for alkaline pretreatment to recover maximum xylan yield were $12-18 \%$ of alkaline concentration, the temperature at $110-120^{\circ} \mathrm{C}$, and steaming time for $37.5-40 \mathrm{~min}$. The FTIR results suggested that the extracted sample was the xylan fraction. The maximum XOS production of $17.35 \pm 0.31 \mathrm{mg}$ XOS per $\mathrm{mL}$ xylan was observed in the run conditions of $6.25 \mathrm{mg}$ enzyme per $\mathrm{g} x y l a n, 9 \mathrm{~h}$ of incubation time, and $5 \%$ of xylan. The results revealed that the xylan extracted from RH by using an effective base couple with the steam application and the enzymatic hydrolysis help to maximize the yield of XOS, which can be further used in functional foods and dietary supplements.
\end{abstract}

Keywords: Xylooligosaccharide, Rice husk, Xylan, Alkaline pretreatment, Enzyme hydrolysis, FTIR

\section{Introduction}

Thailand is one of the leading rice producer and exporter. As per the US Department of Agriculture's Foreign Agricultural Service report, Thailand may produce about 20.4 million tons of rice during 2017-2018. Rice husk (RH) is the major agricultural waste obtained during rice hulling process, and the clearance of agricultural waste by firing cause air pollution. The burning of rice straw in Thailand was attributed to the release of $0.18 \%$ of greenhouse gas (Gadde et al. 2009).

$\mathrm{RH}$ is composed of cellulose (25\%), hemicellulose (25\%), lignin (20\%), ash (17\%), and crude protein (3\%) (Ugheoke and Mamat 2012). The major reducing sugar after acid hydrolysis of rice husk is composed of $17.35 \%$

\footnotetext{
*Correspondence: chaiyavat@gmail.com

${ }^{1}$ Innovation Center for Holistic Health, Nutraceuticals,

and Cosmeceuticals, Faculty of Pharmacy, Chiang Mai University, Chiang

Mai 50200, Thailand

Full list of author information is available at the end of the article
}

of xylose and $4.42 \%$ of glucose (Banerjee et al. 2009). Xylooligosaccharide (XOS) is the molecule containing straight chains of xylose connected by $\beta-1,4-$ glycosidic linkage. In general, linked minimum of $2-20$ xylose molecules are consider as XOS (Vázquez et al. 2000). XOS is well known prebiotic molecule that can selectively support the growth and stimulate the activity of beneficial gut microbiota, particularly Bifidobacterium spp. thereby it confers the health benefits to host (Finegold et al. 2014; Gibson and Roberfroid 1995). XOS reported for anti-cancer, anti-microbial, antioxidant, anti-allergic, anti-infection, anti-inflammatory activities, immunomodulatory, and cholesterol-lowering property (Aachary and Prapulla 2011; Mumtaz et al. 2008). Thus, XOS has been accepted as nutraceutical and feed additive.

The conversion of agricultural waste into useful product reduce the problem of management, treatment, and disposal of agricultural residues. The lignocellulosic rich agricultural residues such as corn cob (Samanta et al. 2012a; Boonchuay et al. 2014), corn stalks (Ergues 
et al. 2012), sugarcane bagasse (Jayapal et al. 2013), cotton stalks, wheat straw, sunflower stalks, tobacco stalks (Akpinar et al. 2009a), pigeon pea stalks (Samanta et al. 2013), and green coconut husks (Jayapal et al. 2014) have been used as raw material for XOS production.

Autohydrolysis, chemical process (acid or alkaline solution treatment), and chemical pretreatment for xylan extraction couple with enzymatic hydrolysis is the possible way to extract XOS from lignocellulosic substrates (Qing et al. 2013). Autohydrolysis is the process for XOS production by heating the lignocellulosic materials with water in specific equipment under controlled condition, while acid hydrolysis is cost effective. Both the techniques produce XOS contaminated with other undesirable substances like lignin, monosaccharides, and furfural (an aldehyde of furan), which cause serious adverse effects like respiratory irritation, lung congestion, hyperplasia, kidney and olfactory epithelial damage, oedema, and inflammation. So further purification process is required to remove the unwanted substances in the product. Nowadays, chemical pretreatment for xylan extraction followed by enzymatic hydrolysis to obtain XOS is an often-preferable method, due to the cost-effective and reduced production time. The alkaline extraction is the important practice to separate xylan from other lignocellulosic materials, which further enhances the efficiency of the enzyme during XOS production (Carvalho et al. 2013; Samanta et al. 2015). In addition, alkaline pretreatment can improve substrate digestibility, the major desired characteristic in XOS production by enzymatic hydrolysis (McIntosh and Vancov 2011).

The current study was aimed to optimize the conditions to achieve high xylan yield in alkaline pretreatment from $\mathrm{RH}$ and XOS production by enzymatic hydrolysis.

\section{Materials and methods Materials}

The rice husk $(\mathrm{RH})$ was obtained from local organic farm in Chiang Mai province, Thailand. The food grade 1,4 beta xylanase (Pentopan ${ }^{\mathrm{TM}}$ MonoBG) was purchased from Novozymes, Denmark. Xylooligosaccharide standards including xylobiose, xylotriose, xylotetraose, and xylopentaose were obtained from Megazyme, Bray, Ireland. Xylose and arabinose standards were obtained from Wako Pure Chemical Industries, Osaka, Japan. The ion exclusion chromatography column, Shodex SUGAR SH1011, was purchased from Showa Denko K.K., Tokyo, Japan. Other chemicals used in the study were of analytical grade.

\section{Rice husk preparation}

The $\mathrm{RH}$ was dried at $50{ }^{\circ} \mathrm{C}$ for $12 \mathrm{~h}$, and powdered by the mechanical blender. The milled $\mathrm{RH}$ was sieved through
$0.595 \mathrm{~mm}$ size (No. 30 ) siever, and stored at room temperature until use.

\section{Optimization of alkaline pretreatment of $\mathrm{RH}$, and XOS production by RSM}

Response surface methodology (RSM) and central composite design (CCD), and RSM and Box-Behnken design (BBD) were used to optimize the condition for alkaline pretreatment of $\mathrm{RH}$, and XOS production using the statistical software package Design Expert, version 10.0., respectively (Stat-Ease Inc., Minneapolis, MN, USA). The basics and statistical analyses of RSM, and its applications in designing the experiment has reported previously (Woraharn et al. 2015, 2016; Chaiyasut et al. 2017). The recovery of xylan was the desired response after $\mathrm{RH}$ pretreatment. The concentration of alkaline (6-18\%), steaming time (15-45 $\mathrm{min})$, and steaming temperature $\left(80-120{ }^{\circ} \mathrm{C}\right)$ have been selected as variable factors to achieve high yield of xylan as per the previous literature (Jayapal et al. 2013; Samanta et al. 2012a, b, 2013). A sum of 20 independent experiments composed of 14 combinations and six center point replicates were performed for alkaline pretreatment (Table 1), and 17 independent experiments performed XOS optimization. The following equation was used in CCD and BBD model.

$$
\begin{aligned}
\mathrm{Y}= & \beta_{0}+\beta_{1} \mathrm{X}_{1}+\beta_{2} \mathrm{X}_{2}+\beta_{3} \mathrm{X}_{3}+\beta_{11} \mathrm{X}_{1}^{2}+\beta_{22} \mathrm{X}_{2}^{2} \\
& +\beta_{33} \mathrm{X}_{3}^{2}+\beta_{12} \mathrm{X}_{1} \mathrm{X}_{2}+\beta_{13} \mathrm{X}_{1} \mathrm{X}_{3}+\beta_{23} \mathrm{X}_{2} \mathrm{X}_{3}
\end{aligned}
$$

where $\mathrm{Y}$ is the predicted response, $\beta_{0}$ is model constant, $\beta \mathrm{i}\left(\beta_{1-3}\right)$ is linear coefficients, $\beta \mathrm{ii}\left(\beta_{11-33}\right)$ is quadratic coefficients, $\beta$ ij (i.e. $\beta_{12}$ ) is cross product coefficients; $X_{1}$, $\mathrm{X}_{2}$ and $\mathrm{X}_{3}$ are independent variables.

For the optimization of XOS production, the enzyme concentration $\left(\mathrm{X}_{1}\right)\left(\mathrm{mg} / \mathrm{g}\right.$ xylan), incubation time $\left(\mathrm{X}_{2}\right)(\mathrm{h})$, and xylan concentration $\left(\mathrm{X}_{3}\right)(\% \mathrm{w} / \mathrm{v})$ were acted as a variable factor while the concentration of XOS as a desirable outcome. The range of enzyme concentration, incubation time, and xylan concentration are 6-12 h, 15-45 min, and $80-120{ }^{\circ} \mathrm{C}$, respectively (Chapla et al. 2012). The experiments were carried out in triplicates.

\section{Alkaline pretreatment of rice husk}

The alkaline pretreatment to $\mathrm{RH}$ was carried out in duplicate according to Samanta et al. (2012a). Briefly, RH powder and alkaline solution (1.91-22.09\% $\mathrm{NaOH}$ depended on the CCD model) was mixed at the ratio of 1:10 (at different alkaline concentration), and subjected to steaming process at various temperature for various duration based on the CCD model. After incubation, the solution was centrifuged at $5000 \mathrm{rpm}$ for $20 \mathrm{~min}$, and the supernatant was acidified with glacial acetic acid until the solution reached $\mathrm{pH} 5$. Then, three volumes of $95 \%$ ice-cold 
Table 1 The variable factors and predicted and observed xylan recovery

\begin{tabular}{|c|c|c|c|c|c|c|}
\hline \multirow[t]{2}{*}{ Std } & \multirow[t]{2}{*}{ Run } & \multicolumn{3}{|l|}{ Factors } & \multicolumn{2}{|l|}{ Xylan recovery } \\
\hline & & $\begin{array}{l}\mathrm{X}_{1}: \text { alkaline } \\
\text { concentration }(\% \mathrm{w} / \mathrm{v})\end{array}$ & $\mathrm{X}_{2}$ : steaming time $(\mathrm{min})$ & $\begin{array}{l}\mathrm{X}_{3} \text { : steaming } \\
\text { temperature }\left({ }^{\circ} \mathrm{C}\right)\end{array}$ & Observed value (\%) & $\begin{array}{l}\text { Predicted } \\
\text { value (\%) }\end{array}$ \\
\hline 14 & 1 & $0(12)$ & $0(30)$ & $1.682(133.64)$ & $54.49 \pm 0.61$ & 52.66 \\
\hline 13 & 2 & $0(12)$ & $0(30)$ & $-1.682(66.36)$ & $11.71 \pm 0.39$ & 12.36 \\
\hline 9 & 3 & $-1.682(1.91)$ & $0(30)$ & $0(100)$ & $5.19 \pm 1.27$ & 7.73 \\
\hline 7 & 4 & $-1(6)$ & $1(45)$ & $1(120)$ & $44.39 \pm 3.42$ & 44.60 \\
\hline 15 & 5 & $0(12)$ & $0(30)$ & $0(100)$ & $16.24 \pm 0.53$ & 13.87 \\
\hline 17 & 6 & $0(12)$ & $0(30)$ & $0(100)$ & $15.07 \pm 2.24$ & 13.87 \\
\hline 6 & 7 & $1(18)$ & $-1(15)$ & $1(120)$ & $8.37 \pm 0.42$ & 13.94 \\
\hline 16 & 8 & $0(12)$ & $0(30)$ & $0(100)$ & $13.67 \pm 1.31$ & 13.87 \\
\hline 18 & 9 & $0(12)$ & $0(30)$ & $0(100)$ & $17.20 \pm 4.30$ & 13.87 \\
\hline 1 & 10 & $-1(6)$ & $-1(15)$ & $-1(80)$ & $8.39 \pm 1.76$ & 10.29 \\
\hline 20 & 11 & $0(12)$ & $0(30)$ & $0(100)$ & $10.69 \pm 0.01$ & 13.87 \\
\hline 10 & 12 & $1.682(22.09)$ & $0(30)$ & $0(100)$ & $14.89 \pm 1.38$ & 11.17 \\
\hline 3 & 13 & $-1(6)$ & $1(45)$ & $-1(80)$ & $3.87 \pm 0.54$ & -0.87 \\
\hline 2 & 14 & $1(18)$ & $-1(15)$ & $-1(80)$ & $10.86 \pm 4.08$ & 11.49 \\
\hline 11 & 15 & $0(12)$ & $-1.682(4.77)$ & $0(100)$ & $11.81 \pm 0.62$ & 7.97 \\
\hline 12 & 16 & $0(12)$ & $1.682(55.23)$ & $0(100)$ & $24.14 \pm 3.98$ & 26.79 \\
\hline 5 & 17 & $-1(6)$ & $-1(15)$ & $1(120)$ & $23.42 \pm 2.09$ & 22.45 \\
\hline 4 & 18 & 1 (18) & $1(45)$ & $-1(80)$ & $9.92 \pm 0.66$ & 11.72 \\
\hline 19 & 19 & $0(12)$ & $0(30)$ & $0(100)$ & $10.16 \pm 1.19$ & 13.87 \\
\hline 8 & 20 & $1(18)$ & $1(45)$ & $1(120)$ & $48.55 \pm 2.12$ & 47.49 \\
\hline
\end{tabular}

ethanol were added to precipitate the xylan fraction and centrifuged at $4480 \times g$ for $10 \mathrm{~min}$ at $4{ }^{\circ} \mathrm{C}$. The xylan precipitate was collected and dried at $55-65{ }^{\circ} \mathrm{C}$ until reach the constant weight. The dried pellet was weighed and stored at room temperature. The exact and relative yield of xylan was calculated according to formula 2 .

Xylan recovery $(\%)=$ Dry weight of extracted xylan $(\mathrm{g}) /$ Weight of the sample $(\mathrm{g}) \times 100$

The optimum condition to recover maximum xylan yield was used for the bulk xylan production and further analysis.

\section{Analysis of extracted xylan}

Hemicellulose quantification of extracted xylan was carried out according to the method of National Renewable Energy Laboratory (NREL) (Sluiter et al. 2008). The hydrolysate was filtered through $0.2 \mu \mathrm{m}$ syringe filter to remove the residues and then determined by HPLC. The sugar sample was subjected to HPLC equipped with refractive index detector (Model 2414, Waters Corporation) using Shodex SUGAR SH1011 column. The analytical column was maintained at $60{ }^{\circ} \mathrm{C}$. The samples were eluted with $0.05 \mathrm{M}$ sulfuric acid with the flow rate of $1.0 \mathrm{~mL} / \mathrm{min}$. The concentration of sugars was determined using peak area of the standard (a mixture of xylose, mannose, and galactose), and the concentration of each sample was expressed as XGM (xylan+galactan + mannan) content (\%) dry hemicellulose basis (Gao et al. 2014).

The functional group identification of alkaline extracted xylan was done using Fourier transform infrared spectrophotometer (Thermo Nicolet, Nexus 470 FTIR) at spectral range of $400-4000,4 \mathrm{~cm}^{-1}$ resolutions, and DTGS with a $\mathrm{KBr}$ window detector. One mg of alkaline extracted xylan was used for FTIR analysis (Samanta et al. 2012a).

\section{Enzyme assay}

The $\beta-1,4$-xylanase activity of commercial enzyme was carried out by using $1 \%$ birchwood xylan (Sigma, St. Louis, $\mathrm{MO}$, USA) solution in citric acid $-\mathrm{Na}_{2} \mathrm{HPO}_{4}$ buffer (pH 6.0) as substrates. An equal volume of both commercial xylanase solution and substrate was incubated at $50{ }^{\circ} \mathrm{C}$ for $10 \mathrm{~min}$ (Bailey et al. 1992). At the indicated interval, the reaction was stopped by adding 3,5-dinitrosalicylic acid (DNS) solution and reducing sugar was quantified (Miller 1959). One unit of the xylanase activity $(\mathrm{U})$ was liberated as the amount of xylanase that released $1 \mu \mathrm{mol}$ of reducing sugar from the substrate xylan per $\min$ at $\mathrm{pH} 6.0,50^{\circ} \mathrm{C}$. 
Enzymatic hydrolysis of alkaline extracted xylan and XOS determination

Enzymatic hydrolysis of rice husk xylan was done by adding $1 \mathrm{~mL}$ of commercial xylanase solution in $9 \mathrm{~mL}$ of alkaline extracted xylan solution in $50 \mathrm{mM}$ citric acid$\mathrm{Na}_{2} \mathrm{HPO}_{4}$ buffer ( $\mathrm{pH} 6.0$ ), and incubated at $50^{\circ} \mathrm{C}$ for various time interval based on BBD model. After incubation reaction was arrested by placing the reaction tube in boiling water bath for $5 \mathrm{~min}$. Then, the XOS mixtures were centrifuged at $6000 \mathrm{rpm}$ for $10 \mathrm{~min}$ and filtered through $0.2 \mu \mathrm{m}$ syringe filter to remove the residues. The samples were quantified by HPLC equipped with refractive index detector (Model 2414, Waters Corporation) using Shodex SUGAR SH1011 column. The samples were eluted with $0.05 \mathrm{M}$ sulfuric acid with flow rate of $0.8 \mathrm{~mL} / \mathrm{min}$. The concentration of sugars was determined using peak area ratio of the mixture xylooligosaccharide standards including xylobiose $\left(\mathrm{X}_{2}\right)$, xylotriose $\left(\mathrm{X}_{3}\right)$, xylotetraose $\left(\mathrm{X}_{4}\right)$, and xylopentaose $\left(\mathrm{X}_{5}\right)$. Glycerol was used as the internal standard. The xylooligosaccharide concentration of samples was expressed as $\mathrm{mg} \mathrm{XOS} / \mathrm{mL}$ xylan.

\section{Statistical analysis}

The alkaline pretreatment of rice husk and enzymatic hydrolysis of alkaline pretreated xylan were carried out in duplicates and triplicates, respectively. All values were expressed as mean $\pm \mathrm{SD}$. The difference between the group means was analyzed by one-way analysis of variance (ANOVA). The differences were considered significant at $P<0.05$.

\section{Results}

\section{Optimization of alkaline pretreatment of $\mathrm{RH}$ for xylan} recovery

The effect of alkaline concentration $\left(\mathrm{X}_{1}\right)$, steaming time $\left(\mathrm{X}_{2}\right)$, and steaming temperature $\left(\mathrm{X}_{3}\right)$ of $\mathrm{RH}$ on the yield were determined by three factors central composite design. Twenty independent experiments with six center points were performed. The predicted recovery of all the center points $\left(X_{1}=12 \% ; X_{2}=30 \mathrm{~min} ; X_{3}=100{ }^{\circ} \mathrm{C}\right)$ were $13.87 \%$, whereas the actual experimental values were varied. About $16.24 \pm 0.53,15.07 \pm 2.24,13.67 \pm 1.31$, $17.20 \pm 4.30,10.69 \pm 0.01$, and $10.16 \pm 1.19 \%$ of recovery was observed in the run numbers $5,6,8,9,11$, and 19 , respectively (Table 1 ).

The analysis of variance, regression coefficients, and response surface plots were carried out using design expert. The analysis of variance of a quadratic model for the yield of alkaline extracted xylan was shown in Table 2.

The regression model for xylan extraction was significant $(P<0.0001)$ with appreciable $\mathrm{R}^{2}(96.16 \%)$ and adjusted $R^{2}$ (92.70\%), and non-significant lack of fit $(P=0.1600)$. The results suggested that the model
Table 2 Analysis of variance for quadratic model of alkaline treatment of rice husk

\begin{tabular}{lcccc}
\hline Source & Sum of squares & Mean square & F-value & $P$-value \\
\hline Model & 3774.96 & 419.44 & 27.80 & $<0.0001$ \\
Residual & 150.88 & 15.09 & & \\
Lack of fit & 108.83 & 21.77 & 2.59 & 0.1600 \\
Pure error & 42.05 & 8.41 & & \\
Cor total & 3925.84 & & & \\
\hline
\end{tabular}

Recovery yield: $R^{2}=96.16 \%, R^{2}$ (adjacent) $=92.70 \%$

equation was adequate for the prediction of recovery yield of alkaline extracted xylan from RH. The CCD-generated a quadratic equation for xylan recovery yield $(\mathrm{Y})$ was as follows:

$$
\begin{aligned}
\mathrm{Y}= & 174.592+2.285 \mathrm{X}_{1}-3.113 \mathrm{X}_{2}-3.286 \mathrm{X}_{3}-0.043 \mathrm{X}_{1}^{2} \\
& +0.006 \mathrm{X}_{2}^{2}+0.016 \mathrm{X}_{3}^{2}+0.032 \mathrm{X}_{1} \mathrm{X}_{2}-0.020 \mathrm{X}_{1} \mathrm{X}_{3} \\
& +0.028 \mathrm{X}_{2} \mathrm{X}_{3} \ldots
\end{aligned}
$$

The estimated regression coefficients revealed that the steaming temperature $(P<0.0001)$ and steaming time $(P=0.0003)$ were had a significant impact in alkaline pretreatment and xylan yield (Table 3 ).

In addition, the steaming temperature and steaming time also exhibited the synergistic effect $(P=0.001)$ during alkaline pretreatment (Fig. 1). The results suggested that both the factors, steaming time and temperature, have elevated the effect on the recovery of alkaline extracted xylan. The maximum xylan yield was, as per Table 1, observed in the run conditions 1,4 , and 20 with the yield of $54.49 \pm 0.61,44.39 \pm 3.42$, and $48.55 \pm 2.12 \%$, respectively. The optimum conditions for alkaline pretreatment to recover maximum xylan yield were $12-18 \%$ of alkaline concentration, the temperature at $110-120^{\circ} \mathrm{C}$, and steaming time for $37.5-40 \mathrm{~min}$.

Table 3 Estimated regression coefficients for alkaline pretreatment from rice husk

\begin{tabular}{lcr}
\hline Term & $\begin{array}{l}\text { Estimated } \\
\text { parameters }\end{array}$ & P-value \\
\hline Alkaline concentration & 2.285 & 0.3541 \\
Steaming time & -3.113 & 0.0003 \\
Steaming temperature & -3.286 & $<0.0001$ \\
Alkaline concentration $\times$ steaming time & 0.032 & 0.0648 \\
Alkaline concentration $\times$ steaming temperature & -0.020 & 0.1079 \\
Steaming time $\times$ steaming temperature & 0.028 & 0.0001 \\
Alkaline concentration $\times$ alkaline concentration & -0.043 & 0.1573 \\
Steaming time $\times$ steaming time & 0.006 & 0.2531 \\
Steaming temperature $\times$ steaming temperature & 0.016 & $<0.0001$ \\
\hline
\end{tabular}



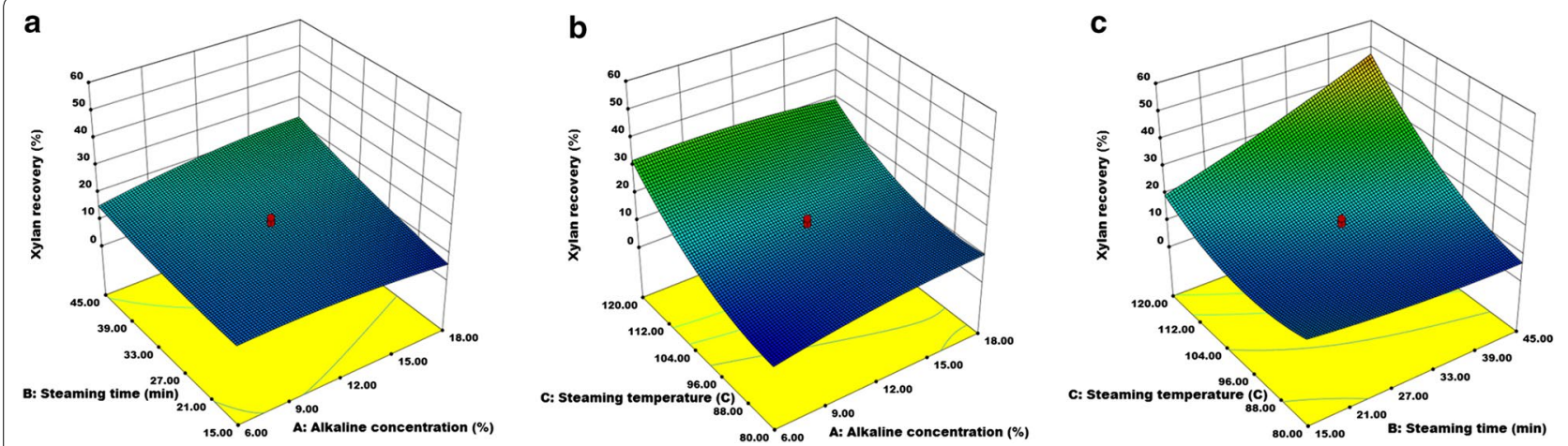

Fig. 1 Response surface plot for alkaline pretreatment of rice husk describing the interaction of independent variables such as alkaline concentration, steaming temperature and steaming time. $\mathbf{a}$ Effect of alkaline concentration and streaming time, $\mathbf{b}$ effect of alkaline concentration and streaming temperature, and $\mathbf{c}$ effect of streaming time and streaming temperature

\section{FTIR analysis}

The extracted xylan was analyzed by FTIR. The FTIR fingerprint pattern was compared with standard beechwood xylan (Fig. 2). FTIR spectra of the sample were closely similar to the standard xylan fraction with high bands at $1600-1000 \mathrm{~cm}^{-1}$. The broad bands were noticed between 3600 and $3200 \mathrm{~cm}^{-1}$. The results clearly suggested that the extracted sample was xylan fraction.

\section{Optimization of xylooligosaccharide (XOS) production}

The influence of enzyme (xylanase) concentration, incubation time, and xylan concentration on XOS production was evaluated. The predicted XOS production of all the center points (enzyme concentration $=3.75 \mathrm{mg} / \mathrm{g}$ of xylan; incubation time $=9 \mathrm{~h}$; xylan concentration $=3 \%$ ) were $13.19 \mathrm{mg}$ XOS per $\mathrm{mL}$ of xylan, whereas the experimental values were varied. About $12.98 \pm 0.01,12.96 \pm 0.65,13.18 \pm 0.47,13.42 \pm 0.47$, and $13.44 \pm 0.24 \mathrm{mg}$ XOS per $\mathrm{mL}$ xylan were recovered in run numbers 1, 3, 6, 8 and 14, respectively (Table 4).

The analysis of variance of a quadratic model for the XOS production was shown in Table 5 . The regression model for xylan extraction was significant $(P<0.0001)$ with appreciable $R^{2}$ (99.47\%) and adjusted $R^{2}(98.80 \%)$, and non-significant lack of fit $(P=0.9278)$. The results suggested that the model equation was adequate for the prediction of XOS production from xylan by enzyme treatment. The BBD generated a quadratic equation for

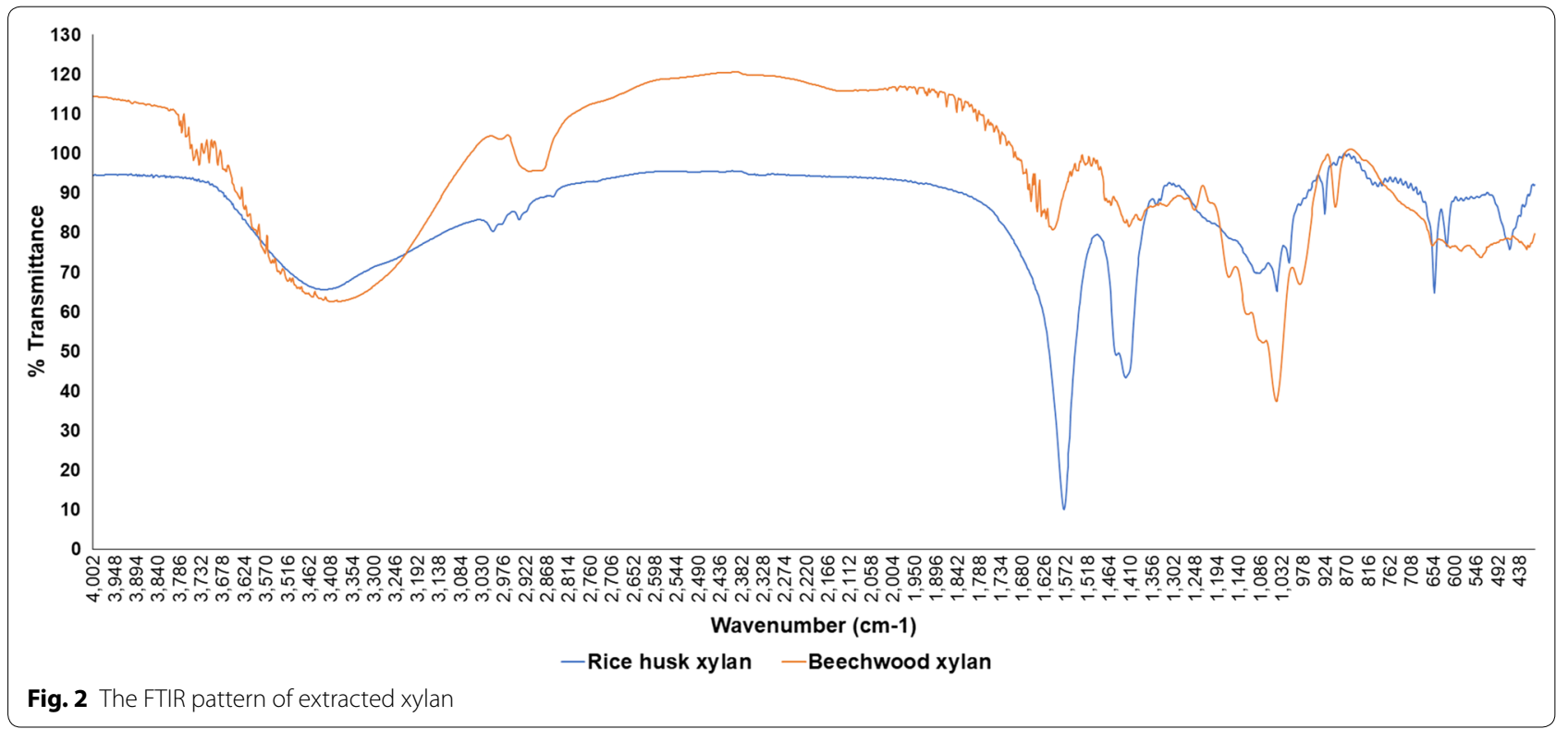


Table 4 The variable factors and predicted and observed xylooligosaccharide yield

\begin{tabular}{|c|c|c|c|c|c|c|}
\hline \multirow[t]{2}{*}{ Std. } & \multirow[t]{2}{*}{ Run } & \multicolumn{3}{|l|}{ Factors } & \multicolumn{2}{|c|}{ Amount of xylooligosaccharide $(\mathrm{mg} / \mathrm{mL})$} \\
\hline & & $\begin{array}{l}\text { X1: enzyme concentration } \\
\text { (mg/g xylan) }\end{array}$ & $\begin{array}{l}\text { X2: incubation } \\
\text { time (h) }\end{array}$ & $\begin{array}{l}\text { X3: xylan } \\
\text { concentration }(\% w / v)\end{array}$ & Observed value & Predicted value \\
\hline 16 & 1 & $0(3.75)$ & $0(9)$ & $0(3)$ & $12.98 \pm 0.01$ & 13.19 \\
\hline 12 & 2 & $0(3.75)$ & $1(16)$ & $1(5)$ & $17.32 \pm 0.79$ & 17.32 \\
\hline 13 & 3 & $0(3.75)$ & $0(9)$ & $0(3)$ & $12.96 \pm 0.65$ & 13.19 \\
\hline 7 & 4 & $-1(1.25)$ & $0(9)$ & $1(5)$ & $16.94 \pm 0.32$ & 16.95 \\
\hline 9 & 5 & $0(3.75)$ & $-1(2)$ & $-1(1)$ & $13.97 \pm 0.14$ & 13.97 \\
\hline 17 & 6 & $0(3.75)$ & $0(9)$ & $0(3)$ & $13.18 \pm 0.47$ & 13.19 \\
\hline 8 & 7 & $1(6.25)$ & $0(9)$ & $1(5)$ & $17.35 \pm 0.31$ & 17.41 \\
\hline 15 & 8 & $0(3.75)$ & $0(9)$ & $0(3)$ & $13.42 \pm 0.47$ & 13.19 \\
\hline 3 & 9 & $-1(1.25)$ & $1(16)$ & $0(3)$ & $13.75 \pm 0.14$ & 13.75 \\
\hline 5 & 10 & $-1(1.25)$ & $0(9)$ & $-1(1)$ & $14.25 \pm 0.31$ & 14.19 \\
\hline 1 & 11 & $-1(1.25)$ & $-1(2)$ & $0(3)$ & $13.05 \pm 0.47$ & 13.11 \\
\hline 2 & 12 & $1(6.25)$ & $-1(2)$ & $0(3)$ & $13.61 \pm 0.14$ & 13.62 \\
\hline 11 & 13 & $0(3.75)$ & $-1(2)$ & $1(5)$ & $17.29 \pm 0.22$ & 17.23 \\
\hline 14 & 14 & $0(3.75)$ & $0(9)$ & $0(3)$ & $13.44 \pm 0.24$ & 13.19 \\
\hline 6 & 15 & $1(6.25)$ & $0(9)$ & $-1(1)$ & $13.88 \pm 0.51$ & 13.87 \\
\hline 10 & 16 & $0(3.75)$ & $1(16)$ & $-1(1)$ & $14.20 \pm 0.03$ & 14.27 \\
\hline 4 & 17 & $1(6.25)$ & $1(16)$ & $0(3)$ & $13.44 \pm 0.16$ & 13.38 \\
\hline
\end{tabular}

Table 5 Analysis of variance for quadratic model of xylooligosaccharide production from xylan

\begin{tabular}{lclcc}
\hline Source & Sum of squares & Mean square & F-value & $\boldsymbol{P}$-value \\
\hline Model & 43.62 & 4.85 & 146.86 & $<0.0001$ \\
Residual & 0.23 & 0.033 & & \\
Lack of fit & 0.023 & $7.544 \mathrm{E}-003$ & 0.14 & 0.9278 \\
Pure error & 0.21 & 0.052 & & \\
Cor total & 43.85 & & & \\
\hline
\end{tabular}

Amount of xylooligosaccharides, $R^{2}=99.47 \%, R^{2}$ (adjacent) $=98.80 \%$

XOS (Y) production from alkaline extracted xylan of $\mathrm{RH}$ was as follows:

$\mathrm{Y}=16.292-0.098 \mathrm{X}_{1}+0.005 \mathrm{X}_{2}-2.807 \mathrm{X}_{3}$

$$
\begin{aligned}
& +0.014 X_{1}^{2}+0.004 X_{2}^{2}+0.580 X_{3}^{2}-0.013 X_{1} X_{2} \\
& +0.039 X_{1} X_{3}-0.004 X_{2} X_{3} \ldots
\end{aligned}
$$

The estimated regression coefficients revealed that the xylan concentration $(P<0.0001)$ had a strong significant impact on XOS production (Table 6). The interactions of all the variables and its impact on XOS production has been represented as response surface plot (Fig. 3). The results suggested that the enzyme concentration and incubation time exhibited a strong interaction effect $(P=0.0468)$ on XOS production (Fig. 3$)$. The maximum XOS production was observed in the run conditions 7 , 2 , 13, and 4 with the yield of $17.35 \pm 0.31,17.32 \pm 0.79$,

\begin{tabular}{lcr}
$\begin{array}{l}\text { Table } 6 \text { Estimated } \\
\text { for xylooligosaccharide production from xylan }\end{array}$ & $\begin{array}{c}\text { regression } \\
\text { Terms }\end{array}$ & $\begin{array}{l}\text { Estimated } \\
\text { parameters }\end{array}$ \\
\hline P-value \\
\hline Enzyme concentration & -0.098 & 0.5936 \\
Incubation time & 0.005 & 0.1700 \\
Xylan concentration & -2.807 & $<0.0001$ \\
Enzyme concentration $\times$ incubation time & -0.013 & 0.0468 \\
Enzyme concentration $\times$ xylan concentration & 0.039 & 0.0686 \\
Incubation time $\times$ xylan concentration & -0.004 & 0.5962 \\
Enzyme concentration $\times$ enzyme concentra- & 0.014 & 0.3457 \\
tion & & \\
Incubation time $\times$ incubation time & 0.004 & 0.0796 \\
Xylan concentration $\times$ xylan concentration & 0.580 & $<0.0001$
\end{tabular}

$17.29 \pm 0.22$, and $16.94 \pm 0.32 \mathrm{mg}$ XOS per $\mathrm{mL}$ xylan, respectively.

\section{Discussion}

XOS has reported for the prebiotic properties, and people are interested in XOS because of its health benefits (Lin et al. 2016). The production of XOS from rice husk $(\mathrm{RH})$ is one of the effective ways to utilize the agricultural wastes. Even though several methods are available to extract xylan from $\mathrm{RH}$, alkaline pretreatment has been used commonly. Alkaline pretreatment accelerates the breakdown of lignocellulosic biomass by smiting the 

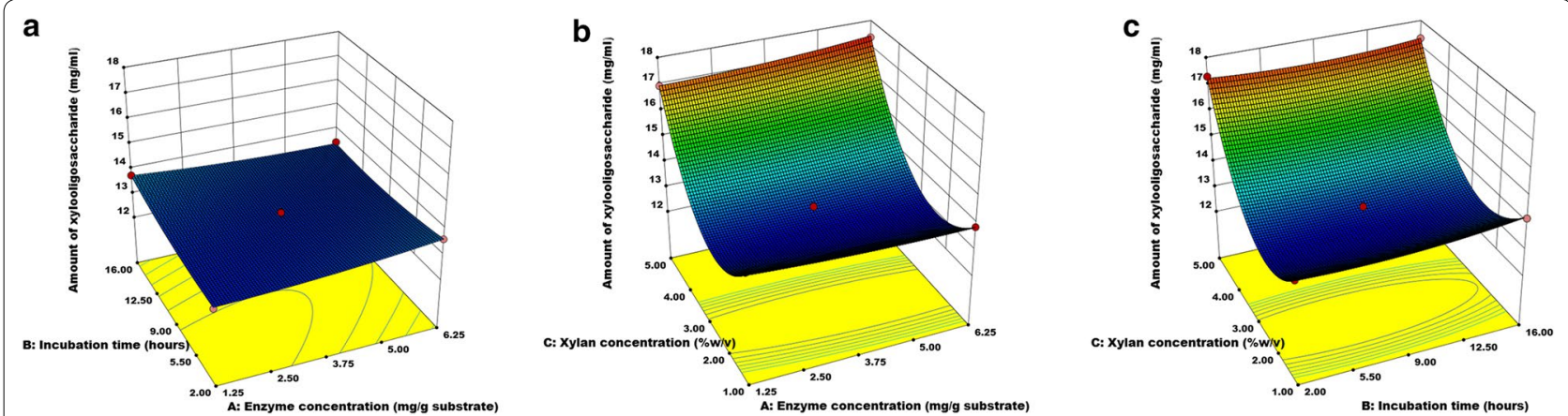

Fig. 3 Response surface plot for enzyme hydrolysis of xylan describing the interaction of independent variables such as enzyme concentration, xylan concentration, and incubation time. a Effect of enzyme concentration and incubation time, $\mathbf{b}$ effect of enzyme concentration and xylan concentration, and c effect of incubation time and xylan concentration

ester bonds in lignin and hemicellulose, which further facilitates the xylan and lignin solubility (Akpinar et al. 2009b; Samanta et al. 2012a).

In this study, $\mathrm{NaOH}$ solution was used for xylan extraction, since it showed the higher yield when compared to other strong bases like $\mathrm{KOH}$ (Jayapal et al. 2013; Samanta et al. 2012a, b, 2013). The steaming time and steaming temperature are the critical factors that influence the xylan yield. About $54.49 \pm 0.61 \%$ of xylan yield was observed with alkaline concentration, steaming time, and temperature of $12 \%, 30 \mathrm{~min}$, and $133.64{ }^{\circ} \mathrm{C}$, respectively (Table 1 ). To confirm the composition of sugar in alkaline pretreated xylan, the hemicellulose quantification was identified and reported as the XGM content. The highest xylan extraction yield in the run conditions of $12 \% \mathrm{NaOH}$ concentration, $30 \mathrm{~min}$ of steaming time, and $133.64{ }^{\circ} \mathrm{C}$ of steaming temperature exhibited the $58.07 \%$ of XMG content per total hemicellulose content. The effect of alkaline concentration, temperature, and extraction time on the recovery yield of hemicellulose has been investigated in several previous studies (Nasir and Saleh 2016; Yilmaz et al. 2012; Zhou et al. 2013). In the current study, the increasing $\mathrm{NaOH}$ concentration was not significantly increased the xylan extraction yield $(P=0.3541)$. This result is consistent with the increasing $\mathrm{NaOH}$ concentration in the range of $10-20 \%$ exhibited the xylan extraction yield from 38.4 to $42.5 \%$. However, this increasing of xylan extraction yield did not statistically important (Yllmaz et al. 2012). The previous report suggested that increasing of extraction temperature from 70 to $95{ }^{\circ} \mathrm{C}$ were raised exhibited the yield of hemicellulose extraction (Cheng et al. 2011; Zhou et al. 2013). In this study, the increased extraction temperature significantly influenced on extraction yield of xylan in the opposite manner $(P<0.0001)$. Additionally, the increased steaming time significantly reduced the alkaline extracted xylan yield $(P=0.0003)$ which is consistent with the earlier study (Yilmaz et al. 2012). Practically, the confirmation of CCD model usually performed to prove the predicted value in the real situation. The alkaline pretreatment condition was changed as $6.47 \%, 15 \mathrm{~min}$, and $80{ }^{\circ} \mathrm{C}$ of alkaline concentration, steaming time, and steaming temperature, respectively, and the yield of xylan was found as $10.32 \pm 0.47 \%$. This actual result exhibited the non-significant data from the predicted value of xylan yield $(P=0.4416)$. The result suggested that the quadratic equation was the effective prediction for the xylan extraction.

The FTIR spectra enable to check the purity and identity of a biomolecule in addition to the indication for the presence of functional groups (Faix 1991; Gonçalves and Ruzene 2001; Ruzene et al. 2008). We performed the FTIR analysis of extracted xylan, and the FTIR pattern showed the high similarity between xylan sample and beechwood xylan (Fig. 2). The rice husk xylan specific bands were observed at 1600$1000 \mathrm{~cm}^{-1}$, whereas the specific bands of wheat straw xylan fall in the range of $1100-1000 \mathrm{~cm}^{-1}$ region (Ruzene et al. 2008). The broad bands were noticed at a wavelength of $3600-3200 \mathrm{~cm}^{-1}$ that was due to the presence of hydroxyl group in the samples. The same band pattern was reported previously (Chaikumpollert et al. 2004; Ruzene et al. 2008). The absorbance at 3422, 2927, 1421, 1251, 1166, 1049, 986 and $897 \mathrm{~cm}^{-1}$ are associated with xylan. The bands between 1166 and $1000 \mathrm{~cm}^{-1}$ are signature bands of xylan. The bands at $897 \mathrm{~cm}^{-1}$ are the indication of $\mathrm{C} 1$ group frequency or ring frequency, was observed in extracted xylan and standard xylan. It is the features of beta xylosidic bonds of each sugar monomers (Gupta et al. 1987). The bands between 1200 and 1000, $897 \mathrm{~cm}^{-1}$, and around $1046 \mathrm{~cm}^{-1}$ were attributed to 4-O-methylglucuronoxylan, $\beta$-glycosidic linkages between the sugar moieties, 
and $\mathrm{C}-\mathrm{O}, \mathrm{C}-\mathrm{C}$ stretching or $\mathrm{C}-\mathrm{OH}$ bending in hemicelluloses, respectively. The absence of pectin in the extracted xylan can be substantiated by the absence of band at $1520 \mathrm{~cm}^{-1}$ (Kačuráková et al. 1999; Kacurakova et al. 1994; Gupta et al. 1987). The FTIR pattern of the sample revealed that the extracted xylan did not present the pectin in their structure.

The xylan is the desirable substance used for further hydrolysis processes including acid and enzymatic hydrolysis to recover XOS with various degree of polymerization. The enzymatic hydrolysis method has been accepted widely to reduce the use of corrosive chemicals and solvents. Furthermore, acid hydrolysis process needs controlled environment to operate and also produce some unwanted substances like monosaccharide and furfural. Due to the specificity of the enzyme, the unwanted contamination was less in enzyme hydrolysis procedure (Aachary and Prapulla 2011; Samanta et al. 2015).

The maximum XOS production of $17.35 \pm 0.31 \mathrm{mg}$ XOS per $\mathrm{mL}$ xylan was observed in the run conditions of $6.25 \mathrm{mg}$ per $\mathrm{g}$ xylan of the enzyme, $9 \mathrm{~h}$ of incubation time, and $5 \%$ of xylan (Table 4). Several studies have been reported the important factors influenced the production yield of XOS such as $\mathrm{pH}$, incubation temperature, incubation time, enzyme dose, and substrate concentration. In this study, three factors including enzyme dose, substrate concentration, and reaction time are the interesting factors for XOS production by the commercial enzyme. From the previous reports, enzyme dose was varied from 2 to $200 \mathrm{U}$ from XOS production presented in previous studies (Brienzo et al. 2010; Chapla et al. 2012; Gowdhaman and Ponnusami 2015; Jayapal et al. 2013; Samanta et al. 2014; Siti-Normah et al. 2012). The increasing of enzyme concentration from 2.65 to $13.25 \mathrm{U}$ were significantly increased the reducing sugars after enzyme hydrolysis (Samanta et al. 2014, 2016). In the present study, the decreasing enzyme concentration exhibited the decreased XOS yield. However, the enzyme dose did not a significant factor after the estimated regression coefficients analysis $(P=0.5936)$. Incubation time is one of the factors that directly influenced by XOS production yield. Similar to this study, the increasing incubation time showed the raised of XOS production yield (Samanta et al. 2014, 2016). The effect of substrate concentration for XOS production was carried out by different concentration of xylan. When xylan concentration was increased, the XOS production yield significantly reduced $(P<0.0001)$. This result agreed with the previous observations of other authors revealed that the dissolution property of xylan reduced when increasing the substrate concentration reflected the decreased of XOS yields, owing to decrease the enzyme activity by the present of impurities in the substrate as well as increase viscosity of substrate solution. Furthermore, the reduction of water content in the medium presented in high concentration of xylan reflected the decreased in XOS production yields (Gowdhaman and Ponnusami 2015; Siti-Normah et al. 2012). The confirmation of BBD model was proved by changing the conditions for XOS production as enzyme concentration $(1.25 \mathrm{mg} / \mathrm{g}$ substrate), incubation time $(2 \mathrm{~h})$, and xylan concentration (1\%), and the actual XOS yield $(13.84 \pm 0.29 \mathrm{mg}$ XOS per $\mathrm{mL}$ xylan) was not significantly different from its predicted value (14.0011 $\mathrm{mg}$ XOS per $\mathrm{mL}$ xylan) from the quadratic equation $(P=0.4249)$. These indicated that the generated equation (Eq. 4) can be used to predict the optimal operation conditions to produce XOS from xylan.

The xylan was extracted efficiently by alkaline pretreatment coupled with the steam application. The steaming time, steaming temperature, the interaction between steaming temperature and steaming time, and interaction of steaming temperature, were the significant factors that directly influence on recovery yield of alkaline extracted xylan. The FTIR analysis showed a typical signal pattern for the hemicellulosic factions. The XOS production was significantly $(P<0.05)$ influenced by xylan concentration, the interaction between enzyme concentration and incubation time, and interaction of xylan concentration. Also, the results revealed that the xylan extracted from $\mathrm{RH}$ as an effective base couple with the steam application and the enzymatic hydrolysis help to maximize the yield of XOS, which can be further used in functional foods and dietary supplements.

\section{Abbreviations}

BBD: Box-Behnken design; CCD: central composite design; DNS: 3,5-dinitrosalicylic acid; FTIR: Fourier-transform infrared spectroscopy; HPLC: high performance liquid chromatography; $\mathrm{KOH}$ : potassium hydroxide; $\mathrm{NaOH}$ : sodium hydroxide; NREL: National Renewable Energy Laboratory; $\mathrm{RH}$ : rice husk; RSM: response surface methodology; XGM: Xylan + Galactan + Mannan; XOS: xylooligosaccharide.

\section{Authors' contributions}

CC involved in the designing of the experiments, analysis of data, and support the manuscript writing. BSS involved in data analysis, manuscript preparation, critical review of the results. NK, SS, NL participated in the RSM study, and statistical analysis. SP was responsible for acquiring the raw experimental data and processing. All authors read and approved the final manuscript.

\section{Author details \\ ${ }^{1}$ Innovation Center for Holistic Health, Nutraceuticals, and Cosmeceuticals, Faculty of Pharmacy, Chiang Mai University, Chiang Mai 50200, Thailand. ${ }^{2}$ Department of Physiology, Faculty of Medicine, Chiang Mai University, Chiang Mai 50200, Thailand. ${ }^{3}$ Health Innovation Institute, Chiang Mai 50200, Thailand.}

\section{Acknowledgements}

We gratefully acknowledge the Royal Golden Jubilee Ph.D. Scholarship under the Thailand Research Fund, National Research Council of Thailand (NRCT), and Chiang Mai University grant (CMU-grant) for their financial support. We 
wish to acknowledge Faculty of Pharmacy and Chiang Mai University, Chiang Mai, Thailand for the necessary provision.

\section{Competing interests}

The authors declare that they have no competing interests.

\section{Availability of data and materials}

All data are fully available within the text.

\section{Consent for publication}

Not applicable.

\section{Ethics approval and consent to participate}

No animal or human subjects were used in this study.

\section{Funding}

Royal Golden Jubilee Ph.D. Scholarship under the Thailand Research Fund, National Research Council of Thailand (NRCT), and Chiang Mai University grant (CMU-grant)

\section{Publisher's Note}

Springer Nature remains neutral with regard to jurisdictional claims in published maps and institutional affiliations.

\section{Received: 9 May 2018 Accepted: 10 July 2018}

Published online: 16 July 2018

\section{References}

Aachary AA, Prapulla SG (2011) Xylooligosaccharides (XOS) as an emerging prebiotic: microbial synthesis, utilization, structural characterization, bioactive properties, and applications. Compr Rev Food Sci Food Saf 10(1):2-16

Akpinar O, Erdogan K, Bostanci S (2009a) Production of xylooligosaccharides by controlled acid hydrolysis of lignocellulosic materials. Carbohydr Res 344(5):660-666

Akpinar O, Erdogan K, Bostanci S (2009b) Enzymatic production of xylooligosaccharide from selected agricultural wastes. Food Bioprod Process 87:145-151

Bailey MJ, Biely P, Poutanen K (1992) Interlaboratory testing of methods for assay of xylanase activity. J Biotechnol 23(3):257-270

Banerjee S, Sen R, Pandey RA, Chakrabarti T, Satpute D, Giri BS, Mudliar S (2009) Evaluation of wet air oxidation as a pretreatment strategy for bioethanol production from rice husk and process optimization. Biomass Bioenergy 33(12):1680-1686

Boonchuay P, Techapun C, Seesuriyachan P, Chaiyaso T (2014) Production of xylooligosaccharides from corncob using a crude thermostable endoxylanase from Streptomyces thermovulgaris TISTR1948 and prebiotic properties. Food Sci Biotechnol 23(5):1515-1523

Brienzo M, Carvalho W, Milagres AM (2010) Xylooligosaccharides production from alkali-pretreated sugarcane bagasse using xylanases from Thermoascus aurantiacus. Appl Biochem Biotechnol 162(4):1195-1205

Carvalho AFA, Neto PO, da Silva DF, Pastore GM (2013) Xylo-oligosaccharides from lignocellulosic materials: chemical structure, health benefits and production by chemical and enzymatic hydrolysis. Food Res Int 51(1):75-85

Chaikumpollert O, Methacanon P, Suchiva K (2004) Structural elucidation of hemicelluloses from Vetiver grass. Carbohydr Polym 57(2):191-196

Chaiyasut C, Pengkumsri N, Sirilun S, Peerajan S, Khongtan S, Sivamaruthi BSS (2017) Assessment of changes in the content of anthocyanins, phenolic acids, and antioxidant property of Saccharomyces cerevisiae mediated fermented black rice bran. AMB Expr 7:114

Chapla D, Pandit P, Shah A (2012) Production of xylooligosaccharides from corncob xylan by fungal xylanase and their utilization by probiotics. Bioresour Technol 115:215-221

Cheng H, Zhan H, Fu S, Lucia LA (2011) Alkali extraction of hemicellulose from depithed corn stover and effects on soda-AQ pulping. BioResources 6(1):196-206
Ergues I, Sanchez C, Mondragon I, Labidi J (2012) Effect of alkaline and autohydrolysis processes on the purity of obtained hemicellulose from corn stalks. Bioresour Technol 103:239-248

Faix O (1991) Classification of lignin from different botanical origins by FT-IR spectroscopy. Holzforschung 45:21-27

Finegold SM, Li Z, Summanen PH, Downes J, Thames G, Corbett K, Dowd S, Krak M, Heber D (2014) Xylooligosaccharide increases bifidobacteria but not lactobacilli in human gut microbiota. Food Funct 5(3):436-445

Gadde B, Menke C, Wassman R (2009) Rice straw as a renewable energy source in India, Thailand, and the Philippines: overall potential and limitations for energy contribution and greenhouse gas mitigation. Biomass Bioenergy 33:1532-1546

Gao X, Kumar R, Wyman CE (2014) Fast hemicellulose quantification via a simple one-step acid hydrolysis. Biotechnol Bioeng 111(6):1088-1096

Gibson GR, Roberfroid MB (1995) Dietary modulation of the human colonic microbiota: introducing the concept of prebiotics. J Nutr 125(6):1401-1412

Gonçalves AR, Ruzene DS (2001) Bleachability and characterization by Fourier transform infrared principal component analysis of Acetosolv pulps obtained from sugarcane bagasse. Appl Biochem Biotechnol 91-93:63-70

Gowdhaman D, Ponnusami V (2015) Production and optimization of xylooligosaccharides from corncob by Bacillus aerophilus KGJ2 xylanase and its antioxidant potential. Int J Biol Macromol 79:595-600

Gupta S, Madan RN, Bansal MC (1987) Chemical composition of Pinus caribuca hemicellulose. Tappi 70:113-114

Jayapal N, Samanta AK, Kolte AP, Senani S, Sridhar M, Suresh KP, Sampath KT (2013) Value addition to sugarcane bagasse: xylan extraction and its process optimization for xylooligosaccharides production. Ind Crops Prod 42:14-24

Jayapal N, Sondhi N, Jayaram C, Samanta AK, Kolte AP, Senani S (2014) Xylooligosaccharides from green coconut husk. In: Proceedings of global animal nutrition conference on climate resilient livestock feeding systems for global food security, Bangalore, India, 20-22 April 2014

Kacurakova M, Ebringerová A, Hirsch J, Hromadkova Z (1994) Infrared study of arabinoxylans. J Sci Food Agric 66:423-427

Kačuráková M, Wellner N, Ebringerová A, Hromádková Z, Wilson RH, Belton PS (1999) Characterization of xylan-type polysaccharides and associated cell wall components by FT-IR and FT-Raman spectroscopies. Food Hydrocoll 13(1):35-41

Lin S, Chou L, Chien Y, Jung-Su Chang J, Lin C (2016) Prebiotic Effects of xylooligosaccharides on the improvement of microbiota balance in human subjects. Gastroenterol Res Pract 2016(2016):5789232

McIntosh S, Vancov T (2011) Optimization of dilute alkaline pretreatment for enzymatic scarification of wheat straw. Biomass Bioenergy 35(7):3094-3103

Miller GL (1959) Use of dinitrosalicylic acid reagent for determination of reducing sugar. Anal Chem 31(3):426-428

Mumtaz S, Rehman SU, Huma N, Jamil A, Nawaz H (2008) Xylooligosaccharide enriched yoghurt: physicochemical and sensory evaluation. Pak J Nutr 7(4):566-569

Nasir MAM, Saleh SH (2016) Characterization of hemicelluloses from oil palm empty fruit bunches obtained by alkaline extraction and ethanol precipitation. Malaysian J Anal Sci 20(4):849-855

Qing Q, Li H, Kumar R, Wyman CE (2013) Xylooligosaccharides production, quantification, and characterization in context of lignocellulosic biomass pretreatment. In: Wyman CE (ed) Aqueous pretreatment of plant biomass for biological and chemical conversion to fuels and chemicals. Wiley, Chichester

Ruzene DS, Silva DP, Vicente AA, Goncalves AR, Teixeira JA (2008) An alternative application to the Portuguese agro-industrial residue: wheat straw. Biotechnol Appl Biochem 147:85-96

Samanta AK, Jayapal N, Kolte AP, Senani S, Sridhar M, Suresh KP, Sampath KT (2012a) Enzymatic production of xylooligosaccharides from alkali solubilized xylan of natural grass (Sehima nervosum). Bioresour Technol 112:199-205

Samanta AK, Senani S, Kolte AP, Sridhar M, Sampath KT, Jayapal N, Devi A (2012b) Production and in vitro evaluation of xylooligosaccharides generated from corn cobs. Food Bioprod Process 90(3):466-474

Samanta AK, Jayapal N, Kolte AP, Senani S, Sridhar M, Mishra S, Prasad CS, Suresh KP (2013) Application of pigeon pea (Cajanus cajan) stalks as raw 
material for xylooligosaccharides production. Appl Biochem Biotechnol 169(8):2392-2404

Samanta AK, Jayapal N, Kolte AP, Senani S, Sridhar M, Dhali A, Suresh KP, Jayaram C, Prasad CS (2014) Process for enzymatic production of xylooligosaccharides from the xylan of corn cobs. J Food Process Preserv 39(6):729-736

Samanta AK, Jayapal N, Jayaram C, Roy S, Kolte AP, Senani S, Sridhar M (2015) Xylooligosaccharides as prebiotics from agricultural by-products: production and applications. Bioact Carbohydr Dietary Fibre 5:62-71

Samanta AK, Kolte AP, Elangovan AV, Dhali A, Senani S, Sridhar M, Suresh KP, Jayapal N, Jayaram C, Roy S (2016) Value addition of corn husks through enzymatic production of xylooligosaccharides. Braz Arch Biol Technol 59:e16160078

Siti-Normah MDS, Sabiha-Hanim S, Noraishah A (2012) Effects of pH, temperature, enzyme and substrate concentration on xylooligosaccharides production. Int J Innov Res Sci Eng Technol 12(6):1181-1185

Sluiter A, Hames B, Ruiz R, Scarlata C, Sluiter J, Templeton D, Crocker D (2008) Determination of structural carbohydrates and lignin in biomass. NREL Laboratory Analytical Procedure NREL/TP-510-42618. National Renewable Energy Laboratory, Golden
Ugheoke IB, Mamat O (2012) A critical assessment and new research directions of rice husk silica processing methods and properties. Maejo Int J Sci Technol 6(3):430-448

Vázquez MJ, Alonso JL, Domínguez H, Parajó JC (2000) Xylooligosaccharides: manufacture and applications. Trends Food Sci Technol 11(11):387-393

Woraharn S, Lailerd N, Sivamaruthi BS, Wangcharoen W, Peerajan S, Sirisattha S, Chaiyasut C (2015) Development of fermented Hericium erinaceus juice with high content of L-glutamine and L-glutamic acid. Int J Food Sci Technol 50:2104-2112

Woraharn S, Lailerd N, Sivamaruthi BS, Wangcharoen W, Sirisattha S, Peerajan S, Chaiyasut C (2016) Evaluation of factors that influence the L-glutamic and $\gamma$-aminobutyric acid production during Hericium erinaceus fermentation by lactic acid bacteria. Cyta-J Food 14(1):47-54

Yılmaz CH, Cekmecelioglu D, Dervisoglu M, Kahyaoglu T (2012) Effect of extraction conditions on hemicellulose yields and optimisation for industrial processes. Int J Food Sci Technol 47(12):2597-2605

Zhou JH, Zhang JY, Li HM, Sun GW, Liang FZ (2013) Extraction of hemicellulose from corn stover by $\mathrm{KOH}$ solution pretreatment and its characterization. Adv Mat Res 821-822:1065-1070

\section{Submit your manuscript to a SpringerOpen ${ }^{\odot}$ journal and benefit from:}

- Convenient online submission

- Rigorous peer review

- Open access: articles freely available online

- High visibility within the field

- Retaining the copyright to your article

Submit your next manuscript at $\boldsymbol{\nabla}$ springeropen.com 